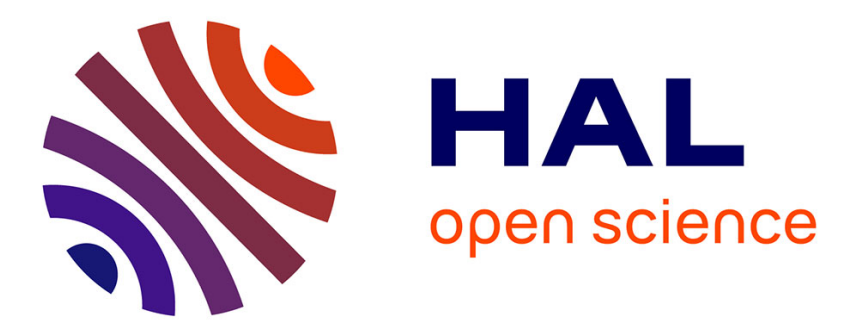

\title{
A Proposal on Patient Transport Decision Making in Multiple Hospitals in a Large-Scale Disaster
}

\author{
Jun Sasaki
}

\section{To cite this version:}

Jun Sasaki. A Proposal on Patient Transport Decision Making in Multiple Hospitals in a LargeScale Disaster. 1st International Conference on Information Technology in Disaster Risk Reduction (ITDRR), Nov 2016, Sofia, Bulgaria. pp.9-19, 10.1007/978-3-319-68486-4_2 . hal-03213129

\section{HAL Id: hal-03213129 \\ https://hal.inria.fr/hal-03213129}

Submitted on 30 Apr 2021

HAL is a multi-disciplinary open access archive for the deposit and dissemination of scientific research documents, whether they are published or not. The documents may come from teaching and research institutions in France or abroad, or from public or private research centers.
L'archive ouverte pluridisciplinaire HAL, est destinée au dépôt et à la diffusion de documents scientifiques de niveau recherche, publiés ou non, émanant des établissements d'enseignement et de recherche français ou étrangers, des laboratoires publics ou privés. 


\title{
A Proposal on Patient Transport Decision Making in Multiple Hospitals in a Large-Scale Disaster
}

\author{
Jun Sasaki \\ Faculty of Software and Information Science of Iwate Prefectural University, Iwate, Japan \\ jsasaki@iwate-pu.ac.jp
}

\begin{abstract}
In 2011, the Great East Japan Earthquake and Tsunami destroyed three prefectural hospitals in Iwate Prefecture, Japan. The author interviewed officers working in the Iwate Medical Central Office as well as medical doctors working in public hospitals, of which there are 25 in Iwate Prefecture. Based on the interviews and several reports this paper describes the problem of patient transport in a large-scale disaster. In such situations, the decision making process is confusing, making it difficult to transport patients efficiently from hospitals in the disaster areas to supporting hospitals. This paper proposes a new decision making method to solve the problem of patient transport. The simulation results of a risk analysis comparing the proposed method with conventional methods are presented.
\end{abstract}

Keywords: Disaster Information, Emergency Management, Patient transport, Medical Information, Decision making.

\section{Introduction}

The Great East Japan Earthquake and Tsunami occurred on 11 March 2011. It destroyed many buildings and killed many people in the Tohoku area of Japan [1]. There are many studies on large-scale disasters, including research into disaster communications [2, 3] and information systems [4]. There are also many reports on medical diseases caused by large-scale disasters [5 - 11]. However, there are few reports on emergency medical activities during large-scale disaster situations. This paper surveyed Iwate Prefectural hospitals' emergency response activities during the Great East Japan Earthquake and Tsunami by interviewing medical doctors of Iwate Prefectural hospitals and officers of Iwate Medical Center and analyzing obtained reports and documents on the disaster affecting. One of the main problems was that the decision making process was confusing, making it difficult to transport patients efficiently from hospitals in the disaster areas to supporting hospitals. This paper proposes a new decision making method for patient transport to solve this problem.

\section{Damage Situation of Iwate Prefectural Hospitals}

Iwate Prefecture is the largest prefecture on Honshu, a main island of Japan. The 
area is approximately $15,280 \mathrm{~km}^{2}$, spanning $200 \mathrm{~km}$ from north to south and $150 \mathrm{~km}$ from east to west. Iwate Prefecture is surrounded by mountains and there are few means of public transport within the region. As such, there are 25 public hospitals throughout Iwate Prefecture, the largest number among Japanese prefectures. All 25 public hospitals are managed by the Iwate Prefectural Medical Office.

Figure 1 shows the locations and damage situations of Iwate prefectural hospitals on 14 March 2011. The hospitals can be classified into two groups: inland-area hospitals and seacoast-area hospitals. A large mountainous area, called the Kitakami Sanchi, sits between the two hospital group areas.

In Figure 1, each hospital is identified by a number. The seacoast-area hospitals were damaged to various degrees by the large tsunami. Hospitals 15, 18 and 20 were classified as completely damaged, whereas hospitals 13, 14, 17 and 19 were damaged but functional. These functional damaged hospitals accepted and supported patients from completely damaged hospital areas. They needed and received support from surrounding undamaged hospitals; for example, hospital 13 was supported by hospital 12 (see Fig. 1).

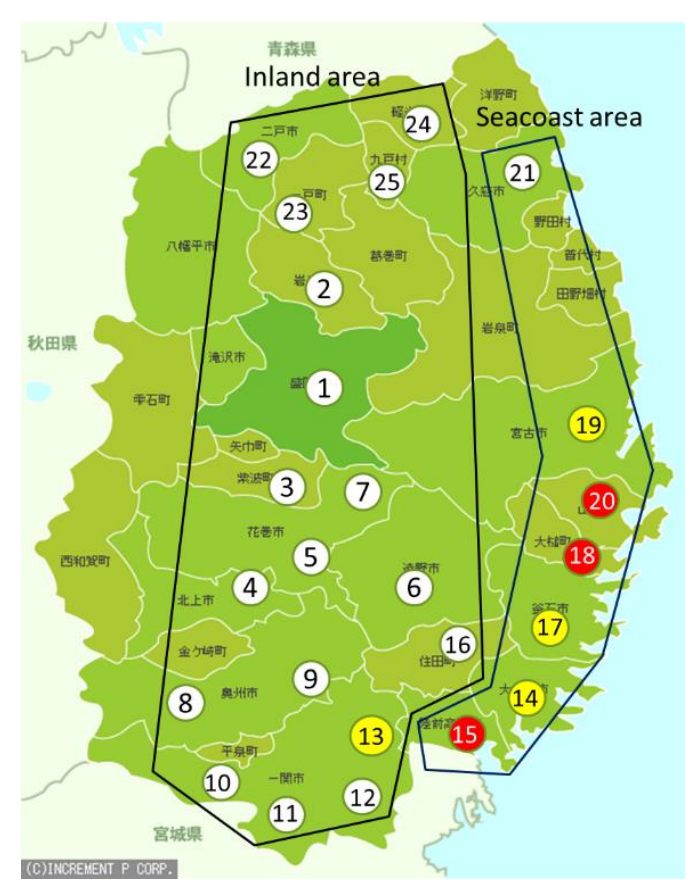

Fig. 1. Damage situation of Iwate prefectural hospitals during the 2011 Great East Japan Disaster.

The author interviewed two medical doctors, one from a functional damaged hospital $(\mathrm{ID}=14)$ and another from a supporting hospital $(\mathrm{ID}=4)$. They were key person and the two doctors played important roles at the time of the disaster. According to the 
reports from the Iwate Prefectural Medical Office, functional damaged hospitals had problems with telecommunications, electricity (including fuel for an auxiliary power generator), water, chemical and medical materials, and food; however, those problems were addressed within three days.

In completely damaged hospital areas, there was a need for clothing, gasoline, portable heating units, food, toiletries, blankets, medicine, diapers and oxygen tanks. Most of those needs were eventually met and requested items were provided by the government, as well as volunteer and support groups.

For several minutes after the earthquake on 11 March 2011, all communications to/from seacoast-area hospital 14 were disrupted; however, the hospital was able to use the emergency wireless phone provided by Iwate Prefecture and the satellite phone provided by the Nippon Telephone and Telegram Corporation. Staff at the hospital connected those telephone lines with the hospital's private wireless phone system. The doctor interviewed for this study stated that the temporary telephone system proved useful during the disaster.

In an emergency meeting after the disaster, the doctor's team planned their disaster response strategy using whiteboards, which they filled with text, tables, figures and maps. When the whiteboards were completely covered, the staff took photos of the boards, erased them and filled them with new text. Thus, they created a record of their activities during the disaster. The second interviewee stated that staff at inland-area hospital 4 wrote on building doors and walls, as well as a whiteboard during an emergency meeting; it was important to make a wide space and tools available for writing.

In Japan, most hospitals use the Emergency Medical Information System (EMIS) to access information about disasters [12]. A color-coded map of Japan on EMIS indicates which areas are: experiencing a disaster; in a state of vigilance; receiving disaster assistance; or training for the early disaster response. In the case of a large-scale disaster, Disaster Medical Assistance Teams (DMATs) are immediately dispatched to the damaged area by helicopters or cars. After the 2011 disaster, DMAT members from various countries as well as those from other parts of Japan arrived at the damaged areas. However, inland-area hospital staff could not determine the number of DMATs that had arrived at the seacoast-area hospitals. In fact, at that time, the Iwate Prefectural Medical Office did not know that 19 DMATs ( 83 members in total) were operating in hospital 14 during the disaster period.

\section{$3 \quad$ Patient Transport from Damaged Hospitals to Supporting Hospitals}

In the Japan disaster of 11 March 2011, many patients in seacoast area of Iwate Prefecture were transported to inland-area hospitals, which were better equipped to provide medical care, using ambulances and helicopters.

Figure 2 shows the number of inbound patients per month transported from seacoastarea hospitals to inland-area hospital 4 . The number of patients transported decreased rapidly after the disaster. In the early disaster response period, the number of patients transported by helicopter transport was relatively large (50\% of ambulance transport). 


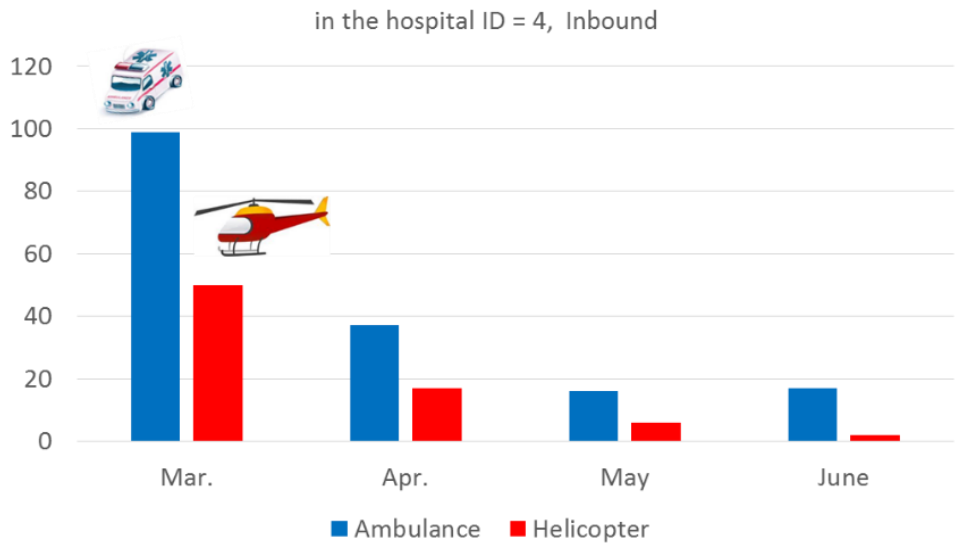

Fig. 2. Number of inbound patients transported from seacoast-area hospitals to inland-area hospital 4.

Figure 3 shows the number of outbound patients transported from seacoast-area hospital 14 to inland-area hospitals. Most of those patients were transported by ambulance in March 2011.

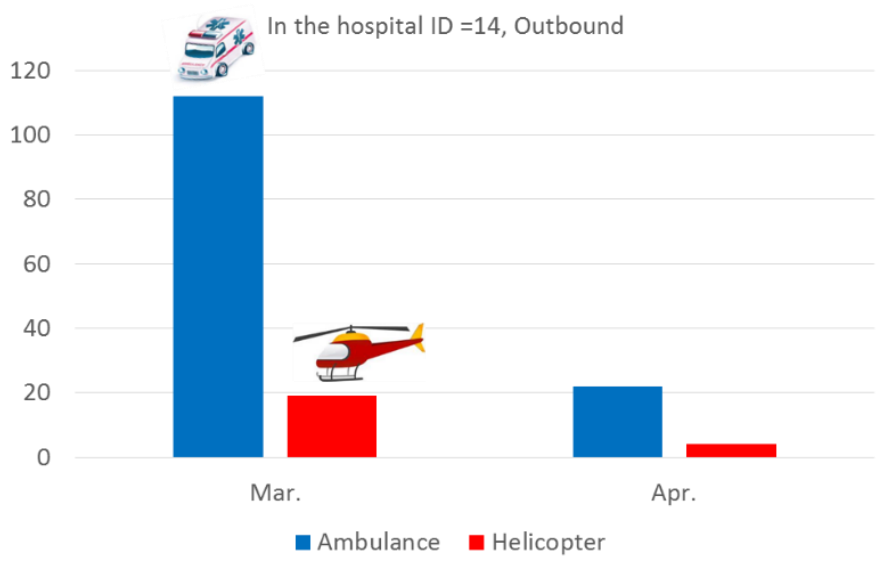

Fig. 3. Number of outbound patients transported from seacoast-area hospital 14 to inland-area hospitals

Table 1 shows the number of patients transported between Iwate prefectural hospitals from 11 March to 31 March 2011. The number of patients transported from seacoast area hospitals 14, 17 and 19, and the number of received patients at inland-area hospitals 1, 2, 4, 6, 8 and 12 was large (>10). According to the interviewee from seacoast-area hospital 14, the complex arrangement of patient transport was carried out on an individual basis via telephone and facsimile. Ideally, patient transport should be carried out immediately and intensively after a disaster using many ambulance cars and 
helicopters. Rapid decision making is required to transport patients in large-scale disaster situations. However, it can be difficult to quickly decide on the destinations for patient transport in an emergency case. This study aims to develop a rapid decision making method for patient transport in large-scale disaster situations. The remainder of this paper introduces a case study and the proposed patient transport method for Iwate prefectural hospitals.

Table 1. Number of patients transported between Iwate prefectural hospitals (from a seacoastarea hospital to an inland-area hospital) from 11 March to 31 March 2011.

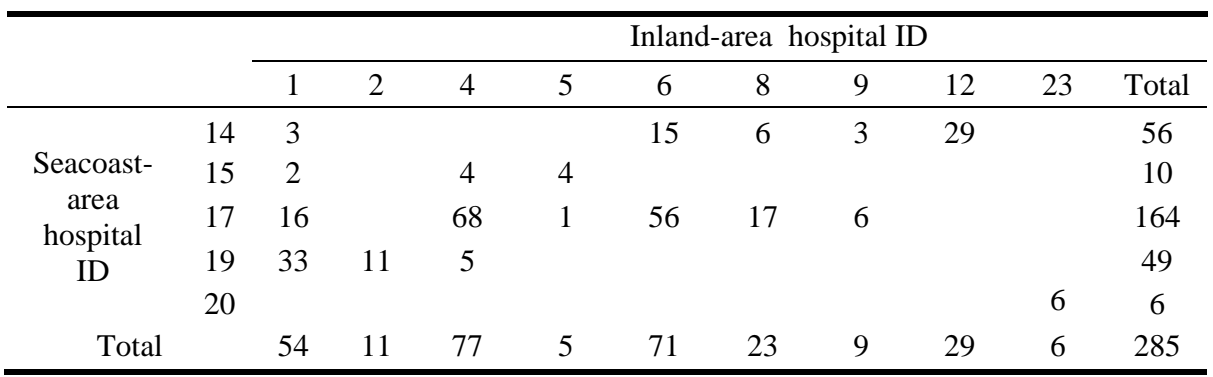

\section{$4 \quad$ Patient Transport in March 2011}

The method of patient transport is usually decided according to the patient condition, transportation time and number of patients able to be accepted by the destination hospital. If the number of patients is large, as is often the case during a large-scale disaster, patients must be transported rapidly to supporting hospitals without thorough consideration of each patient's condition.

Table 2 shows the average transportation time (minutes) by car between seacoastarea hospitals (column) and inland-area hospitals (line) in Iwate Prefecture. The "ID" numbers correspond to the same hospitals as in Fig. 1. Transport time (minutes) was calculated as the shortest distance between hospitals according to Google Maps.

Table 2. Usual transportation time (minutes) between seacoast area hospitals (column) and inland-area hospitals (line) in Iwate Prefecture by car.

\begin{tabular}{cccccccccccccc}
\hline ID & 1 & 2 & 4 & 5 & 6 & 8 & 9 & 10 & 12 & 21 & 22 & 23 & 24 \\
\hline 14 & 118 & 137 & 87 & 74 & 64 & 86 & 79 & 91 & 76 & 208 & 168 & 156 & 172 \\
15 & 113 & 135 & 85 & 73 & 61 & 75 & 77 & 72 & 52 & 206 & 166 & 155 & 170 \\
17 & 110 & 133 & 83 & 70 & 41 & 94 & 81 & 117 & 106 & 182 & 164 & 152 & 167 \\
19 & 123 & 165 & 149 & 136 & 106 & 163 & 147 & 187 & 178 & 97 & 159 & 194 & 138 \\
20 & 128 & 170 & 133 & 120 & 91 & 147 & 131 & 159 & 142 & 126 & 188 & 186 & 167 \\
\hline
\end{tabular}

Table 3 shows the number of patients able to be accepted by supporting hospitals.

Figure 4 shows the actual number of patient transfers after the large tsunami. This figure is based on the numbers shown in Table 1. Arrows indicate the destination of the 
patient transfer, and the arrow thickness indicates the number of transport patients. Hospitals 17 and 14 are relatively large hospitals. During the Great East Japan Earthquake and Tsunami disaster if 2011, medical doctors at the disaster site negotiated with supporting hospitals on patient transfers on a case by case basis. The first problem with that process was that it required a long time and represented a burden to the doctors who were needed for the decision making regarding patient transport. The second problem was a lack of coordination. As shown in Table 3, for example, although one hospital (ID $=5$ ) had no capacity to accept further patients, 5 patients were transported to that hospital.

Table 3. Usual transportation time (minutes) between seacoast area hospitals (column) and inland-area hospitals (line) in Iwate Prefecture by car.

\begin{tabular}{cccccccccccccc}
\hline ID & 1 & 2 & 4 & 5 & 6 & 8 & 9 & 10 & 12 & 21 & 22 & 23 & 24 \\
\hline 14 & 118 & 137 & 87 & 74 & 64 & 86 & 79 & 91 & 76 & 208 & 168 & 156 & 172 \\
15 & 113 & 135 & 85 & 73 & 61 & 75 & 77 & 72 & 52 & 206 & 166 & 155 & 170 \\
17 & 110 & 133 & 83 & 70 & 41 & 94 & 81 & 117 & 106 & 182 & 164 & 152 & 167 \\
19 & 123 & 165 & 149 & 136 & 106 & 163 & 147 & 187 & 178 & 97 & 159 & 194 & 138 \\
20 & 128 & 170 & 133 & 120 & 91 & 147 & 131 & 159 & 142 & 126 & 188 & 186 & 167 \\
\hline
\end{tabular}

Table 4. Number of patients able to be accepted by supporting hospitals

\begin{tabular}{ccccccccccccccc}
\hline ID & 1 & 2 & 4 & 5 & 6 & 8 & 9 & 10 & 12 & 21 & 22 & 23 & 24 & Total \\
\hline $\mathrm{Na}$ & 157 & 5 & 78 & 0 & 12 & 80 & 3 & 64 & 59 & 41 & 40 & 36 & 5 & 580 \\
\hline
\end{tabular}

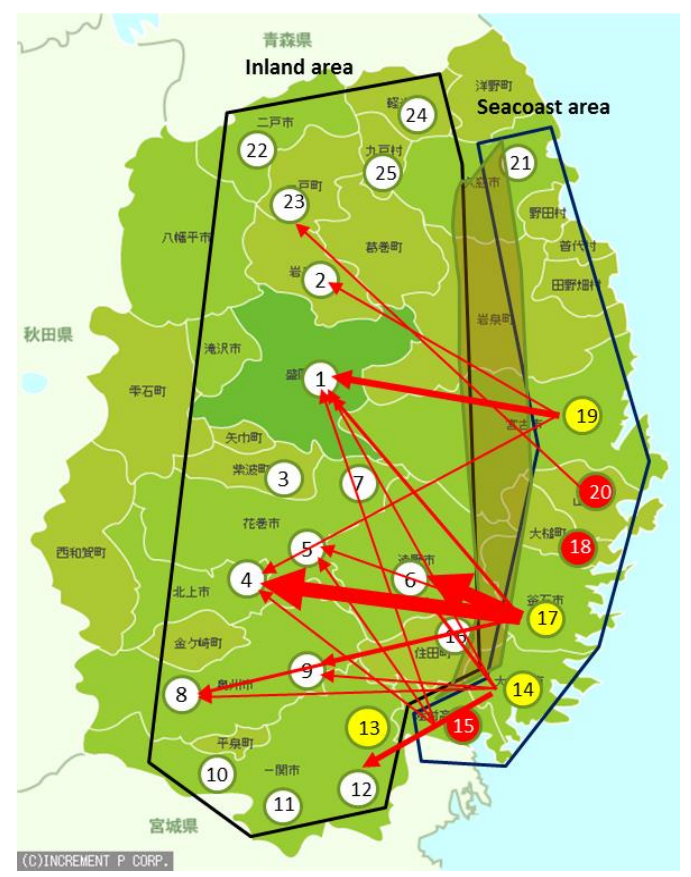

Fig. 4. Map of patient transportation from 11 March to 31 March 2011. 


\section{$5 \quad$ Proposed Method}

In the above case, doctors in damaged hospitals had to negotiate with several hospitals to decide on the hospital to which to transport the patient. As mentioned, this process was time consuming and required considerable effort on the part of the doctors. In the case of a large-scale disaster, this type of negotiation is not feasible because many patients need to be transported.

This paper proposes calculating the risk for each destination hospital, selecting the hospital with the lowest risk, and transporting the patient to that hospital without negotiation. Here, risk is determined based on the transport time and the number of patients able to be accepted by the supporting hospital. The value of risk $\left(r_{k}\right)$ of supporting hospital $\mathrm{k}$ is calculated using following equation.

$$
r_{k}=T_{t k} / N_{a k}
$$

where Ttk is the transportation time between the damaged hospital and the supporting hospital (ID = k), and Nak is the number of patients able to be accepted by the supporting hospital (ID $=\mathrm{k}$ ).

Table 4 shows the value of risk, which is calculated by equation (1) using transportation time (minutes) shown in Table 2 and the number of acceptable patient given in Table 3. There are four obviously high-risk hospitals (ID = 2, 5, 9 and 24). These hospitals are removed from the candidate pool of destination hospitals. The number of transport patients (nak) from the damaged hospital (ID = a) to the supporting hospital (ID $=\mathrm{k}$ ) can be calculated using the following equation.

$$
n_{a k}=\frac{N_{a}}{r_{a k} \sum_{i=1}^{n} \frac{1}{r_{a i}}}
$$

where $N$ is the total number of patients in the damaged hospitals, $\mathrm{n}$ is the total number of supporting hospitals, and $r_{a k}$ is the value of risk of transportation from a damaged hospital (ID $=a)$ to a supporting hospital $(I D=k)$.

Table 5. Value of risk calculated by equation (1) using Table 2 and Table 3.

\begin{tabular}{cccccccccccccc}
\hline ID & 1 & 2 & 4 & 5 & 6 & 8 & 9 & 10 & 12 & 21 & 22 & 23 & 24 \\
\hline 14 & 0.752 & 27.4 & 1.115 & - & 5.333 & 1.075 & 26.33 & 1.422 & 1.288 & 5.073 & 4.20 & 4.333 & 34.4 \\
15 & 0.720 & 27.0 & 1.090 & - & 5.083 & 0.938 & 25.67 & 1.125 & 0.881 & 5.024 & 4.15 & 4.306 & 34.0 \\
17 & 0.701 & 26.6 & 1.064 & - & 3.417 & 1.175 & 27.00 & 1.828 & 1.797 & 4.439 & 4.10 & 4.222 & 33.4 \\
19 & 0.783 & 33.0 & 1.910 & - & 8.833 & 2.038 & 49.00 & 2.922 & 3.017 & 2.366 & 3.975 & 5.389 & 27.6 \\
20 & 0.815 & 34.0 & 1.705 & - & 7.583 & 1.838 & 43.67 & 2.484 & 2.407 & 3.073 & 4.70 & 5.167 & 33.4 \\
\hline
\end{tabular}

\section{Simulation Results and Comparison}

Table 5 shows the simulation results of the number of patients transported from affected hospitals to supporting hospitals based on the proposed method. The numbers of patients transported using the conventional method are compared with those derived using the proposed method. In previous method, supporting hospitals 2, 5, 6 and 9 had exceeded their capacity for acceptable number of patients. In those hospitals, patients 
might have had to be transported to other hospitals. In contrast, using the proposed method, patients were transported to hospitals with sufficient capacity to admit them.

Figure 5 shows the simulation results of patient transport using the proposed method. This figure is based on the calculation results shown in Table 4. Arrows indicate the destination of the patient transports, and the arrow thickness indicates the number of patients transported. We can see that the patient transport is distributed more widely among supporting hospitals compared with Fig. 4. If helicopters can be used, the transport distance is less of an issue compared with hospital capacity. Therefore, in the proposed method, acceptable capacity is more highly prioritized than transport distance.

The number of arrows, indicating transfers to destination hospitals, is greater in proposed model (see Fig. 5) compared with the current method (see Fig. 4). However, in a large-scale disaster situation, there is no time to carry out conventional negotiations. Because the time is the highest priority, patients should be transported from damaged hospitals to supporting hospitals as soon as possible. Before such transfers can take place, supporting hospitals and damaged hospitals must provide information to a control center in the area regarding the number of patients able to be accepted and those to be transported, respectively. The control center would allocate the patients among supporting hospitals based on the proposed method. The proposed method of decision making will thus be more efficient than the conventional method.

Table 6. Value of risk calculated by equation (1) using Table 2 and Table 3.

\begin{tabular}{|c|c|c|c|c|c|c|c|c|c|c|c|c|c|c|c|}
\hline \multirow{2}{*}{ ID } & \multicolumn{15}{|c|}{ Supportable hospitals } \\
\hline & & 1 & 2 & 4 & 5 & 6 & 8 & 9 & 10 & 12 & 21 & 22 & 23 & 24 & Total \\
\hline \multirow{5}{*}{$\begin{array}{l}\text { Af- } \\
\text { fected } \\
\text { hospital }\end{array}$} & 14 & 14 & - & 10 & - & 2 & 9 & - & 7 & 8 & 2 & 2 & 2 & - & 56 \\
\hline & 15 & 3 & - & 2 & - & 0 & 2 & - & 1 & 2 & 0 & 0 & 0 & - & 10 \\
\hline & 17 & 44 & - & 29 & - & 9 & 26 & - & 17 & 17 & 7 & 8 & 7 & - & $\begin{array}{c}16 \\
4\end{array}$ \\
\hline & 19 & 16 & - & 8 & - & 1 & 6 & - & 4 & 4 & 5 & 3 & 2 & - & 49 \\
\hline & 20 & 2 & - & 1 & - & 0 & 1 & - & 1 & 1 & 0 & 0 & 0 & - & 6 \\
\hline \multicolumn{2}{|c|}{$\begin{array}{l}\text { a) Proposed } \\
\text { method }\end{array}$} & 79 & 0 & 50 & 0 & 12 & 44 & 0 & 30 & 32 & 14 & 13 & 11 & 0 & 285 \\
\hline \multicolumn{2}{|c|}{ Total (a) /Na } & $50 \%$ & $0 \%$ & $64 \%$ & - & $100 \%$ & $55 \%$ & $0 \%$ & $47 \%$ & $54 \%$ & $34 \%$ & $33 \%$ & $31 \%$ & $0 \%$ & $49 \%$ \\
\hline \multicolumn{2}{|c|}{$\begin{array}{l}\text { b) Previous } \\
\text { method }\end{array}$} & 54 & 11 & 77 & 5 & 71 & 23 & 9 & 0 & 29 & 0 & 0 & 6 & 0 & 285 \\
\hline \multicolumn{2}{|c|}{ Total (b) /Na } & $34 \%$ & $220 \%$ & $99 \%$ & - & $592 \%$ & $29 \%$ & $300 \%$ & $0 \%$ & $49 \%$ & $0 \%$ & $0 \%$ & $17 \%$ & $0 \%$ & $49 \%$ \\
\hline \multicolumn{2}{|l|}{$\mathrm{Na}$} & 157 & 5 & 78 & 0 & 12 & 80 & 3 & 64 & 59 & 41 & 40 & 36 & 5 & 580 \\
\hline
\end{tabular}

\section{$7 \quad$ Backup and Sharing of Patient Information}

Emergency medical services [12] comprise an organized and collaborative effort among several organizations to provide care in order to transport sick or injured patients to hospital. Although such collaboration is important, there is no time to make decisions to transport individual patients in the case of large-scale disasters. In the large tsunami disaster of 11 March 2011 in Japan, three hospitals were completely destroyed, and many patients' medical records disappeared. To provide consistent emergency and 
long-term medical and health care service in a disaster area, it is important to backup and share patient data.

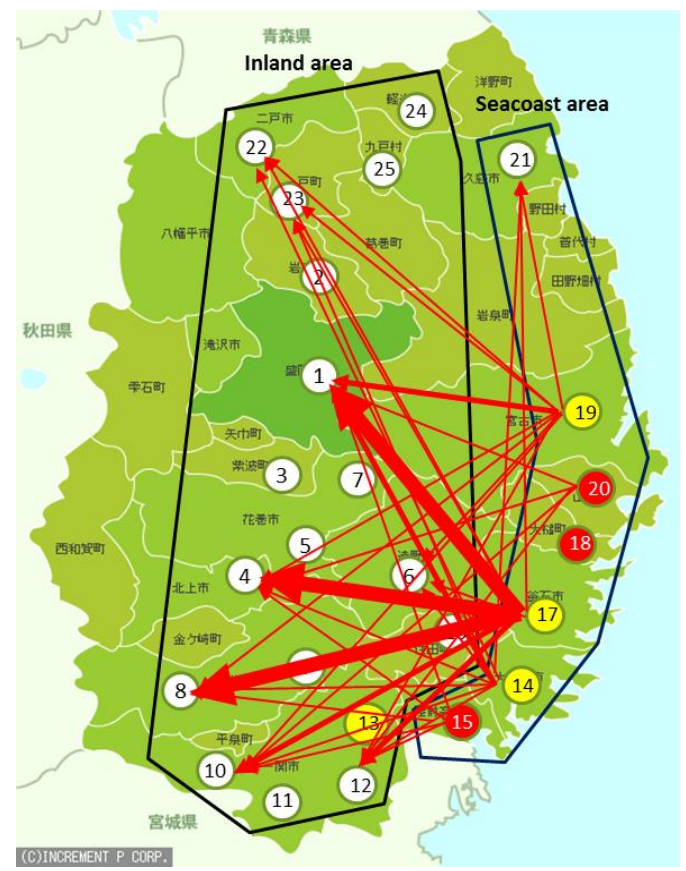

Fig. 5. Simulation results of patient transport using the proposed method.

Figure 6 shows the proposed backup and information sharing method.

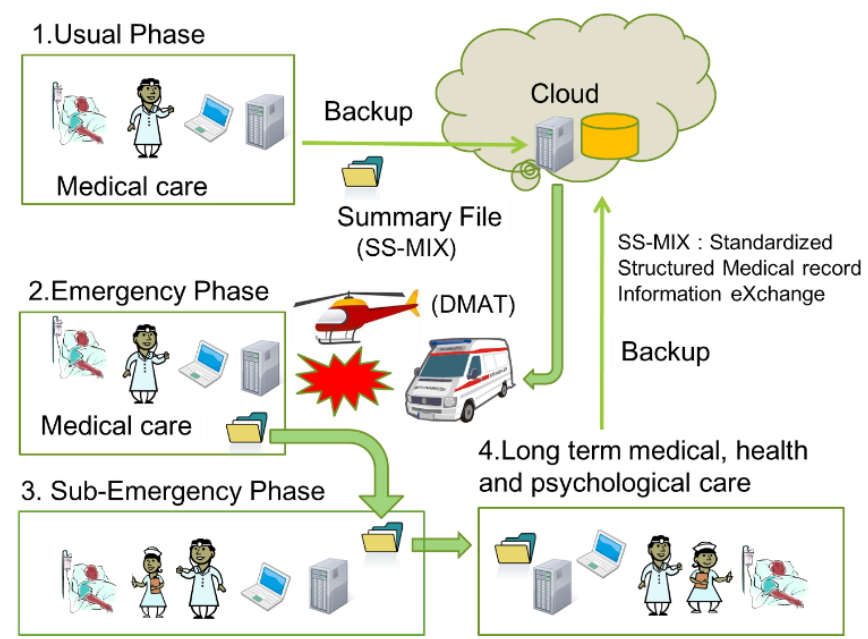

Fig. 6. Proposed backup and information sharing method. 
The author proposes the medical information should be copied to a cloud server for backup purposes. The size of medical information files tends to be large, especially if they include medical image data. The author proposes using the standardized structured medical record information exchange (SS-MIX) system to backup patient data and restart medical care after a disaster. In case of an emergency, the supporting hospital can use the SS-MIX data in the cloud server, and medical care can resume immediately. These data can be used for the patients in the sub-emergency phase, such as those living in shelters or temporary housing. Further, it will be useful in the case of long-term health and psychological care.

\section{Conclusions}

This paper described the condition and emergency response activities of Iwate prefectural hospitals following the Great East Japan Earthquake and Tsunami disaster based on interviews and documents provided by two medical doctors and an officer from the Iwate Medical Central Office. A new method of decision making for patient transportation in the case of a large-scale disaster was proposed. The effectiveness of the proposed method was compared with current methods by simulation.

Patient transportation, medical information backup and information sharing issues in disaster situations warrant further study. The purpose of the study was to propose an efficient decision making process and data storage/sharing system that can be applied in large-scale disaster situations in Iwate Prefecture, other areas of Japan and other nations.

\section{Acknowledgments}

The author would like to thank Professor Yuko Murayama of Tsuda College, for fruitful discussions. The author also deeply appreciates the participation of the two doctors from Iwate prefectural hospitals and officers from the Iwate Prefectural Medical Office who provided interviews and significant reports, respectively. The names of the interviewees and hospitals are omitted for anonymity. This research was supported by JSPS KAKENHI Grant Number 15K01950.

\section{References}

1. Norio, O., Kajitani, Y., Shi, P., Tatano, H.: The 2011 Eastern Japan Great Earthquake Disaster: Overview and Comments. Int. J. Disaster Risk Sci. 2 (1), 34-42 (2011).

2. Murayama Y.: Issues in Disaster Communications. Journal of Information Processing 22 (4), 558-565 (Oct. 2014).

3. Wilensky H.: Twitter as a Navigator for Stranded Commuters during the Great East Japan Earthquake. In: Proceedings of the $11^{\text {th }}$ International ISCRAM ConferenceUniversity Park, Pennsylvania, USA (May 2014). 
4. De Walle, B. V., Turoff, M.: Starr Roxanne Hilts edited: Information System for Emergency Management, AMIS, M.E. Sharpe, Inc. (2010).

5. Aoki, T., Fukumoto, Y., Yasuda, S., Sakata, Y., Ito, K., Takahashi, J., Miyata, S., Tsuji, I., Shimokawa, H.: The Great East Japan Earthquake Disaster and cardiovascular disease, European Heart Journal 33, 2796-2803 (2012).

6. Yamada, S., Hanagama, M., Kobayashi, S., Satou, H., Tokuda, S., Niu, K., Yanai, M.: The impact of the 2011 Great East Japan Earthquake on hospitalization for respiratory disease in a rapidly aging society: a retrospective descriptive and cross-sectional study at the disaster base hospital in Ishinomaki, BMJ Open 2013, 3:e000865.doi:10.1136/bmjopen-2012-000865.

7. Ogawa, S., Ishiki, M., Nako, K., Okamura, M., Senda, M., Sakamoto, T., Ito, S.: Effects of the Great East Japan Earthquake and huge tsunami on glycaemic control and blood pressure in patients with diabetes mellitus, BMJ Open 2012, 2:e000830.doi:10.1136/ bmjopen-2012-000830.

8. Takahashi, T., Goto, M., Yoshida, H., Sumino, H., Matsui, H.: Infectious Disease after the 2011 Great East Japan Earthquake, Journal of Experimental and Clinical Medicine 4(1), 20-23 (2012).

9. Leor, J., Poole, W. K., Kloner, R. A.: Sudden Cardiac Death Triggered by an Earthquake, The New England Jounal of Medicine.

10. Nohara, M.: Impact of the Great East Japan Earthquake and tsunami on health, medical care and public health systems in Iwate Prefecture, Japan, 2011, WPSAR 2 (4) (2011).

11. Schooley, B., Murad, A., Abed Y., Horan, T.: A mHealth System for Patient Handover in Emergency Medical Services. In: Proceedings of the $10^{\text {th }}$ International ISCRAM Conference, Baden-Baden, Germany (May 2013).

12. Emergency Medical Information System (Japanese), URL (Sep. 9, 2015) https://www.wds.emis.go.jp/. 